Salicylsäure: braungrün, in dunkelbraungrün übergehend. Santonin: keine Reaction.

Solanin: kaffeebraun, nach einiger Zeit färbt sich der Rand des Tropfens carmoisinroth, gegen die Mitte za gelb, noch weiter zur Mitte schmutzig grün, bis sich nach circa zwei Stunden der Tropfen in eine gelatinöse, intensiv dunkelviolette Masse umwandelt.

Strychnin: blauviolett, kurz darauf ändert sich die Farbe in rothviolett, carminroth und schliesslich in prachtvoll feuerroth. Wird das Strychnin mit dem Reagens nur befeuchtet, so färbt es sich sehr schön veilchenblau.

Veratrin: braunroth, nach und nach dunkelrothviolett werdend.

Reaction auf Acetanilid. Denig ès*) weist darauf hin, dass Acetanilid (wie alle Anilide überhaupt) beim Kochen mit einer alkoholischen Lösung von Natriumhypobromid einen gelbrothen Niederschlag gibt, während gleichzeitig ein deutlicher Geruch nach Methylcyanür anftritt.

\title{
Auf folgende ähnliche Reactionen des Carbazols und Pyrrols
} macht Samuel C. Hooker**) aufmerksam. 1) Carbazol wie Pyrrol gibt die Fichtenspanreaction. 2) Carbazol wie Pyrrol liefert eine dunkelblaue Verbindung mit Isatin und Schwefelsäure. 3) Carbazol und Pyrrol geben beide zwei verschiedene Substanzen mit Benzochinon; die eine ist eine in Aether leicht lösliche, violettrothe Verbindung, die andere ein gritner, in Aether unlöslicher Körper. 4) Pyrrol gibt gleich dem Carbazol eine in rothen Nadeln krystallisirende Verbindung mit Pikrinsäure. Hinsichtlich der Einzelheiten über Ausführung und theoretische Bedeutung der Reactionen muss ich auf das Original verweisen.

Ueber die Reactionen einiger Phenole und analoger Körper mit Chloroform und Alkalien hat G. A. Raupenstrauch $\left.{ }^{* * *}\right)$ Mittheilungen gemacht. Er hebt hervor, dass die Farbenreaction, die bei der Einwirkung ron Chloroform und Alkalien auftritt, für alle Phenole und phenolartigen Körper charakteristisch ist und deshalb nicht ohne weiteres auf einen bestimmten Körper zu schliessen gestattet. Ueber die Em-

*) Bull. Soc. Pharm. Bord. durch Chemiker-Zeitung 13, R. 11.

**) Ber. d. deutsch. chem. Gesellsch. zu Berlin 21, 3299.

***) Pharmaceutische Zeitung 33, 737; durch Chemisches Centralblatt [4. F.] 1. 1, 36 and Chemiker-Zeitung 13, R. 9. 